On the 19th Mr. R. S. Ryce opened the abdomen through a median incision and the large intestine appeared, looking like liver and greattydisted a collapsed, perming the abdomen at its splente flexure. The opening in the diaphragm was easily enough enlarged with the flecers and a portion of the bow pulled down return of all the bowel, moreover, the patient's condition did not justify any further operative procedure, and the abdomen wa closed. For a few days fæces were passed through the tube as well as per rectum, and then it was removed.

The patient, a blacksmith, has been warned that he will have to seek lighter work. He complains now at times of flatulence, and it is not improbable that another operation may be required to free the adhesions, return the prolapsed colon, and repair the diaphragm. To do this really well it seems to me imperative to resect at least two ribs and so get at the diaphragm from above. Mr. Ryce tells me that the opening in the diaphragm was circular and well to the left of the csophagus, also that it was not connected with either arcuate ligament and that it was just such an opening as might have been made by a bullet.

Llwynwern, Glam.

\section{TWO CASES OF RELAPSING FEVER.}

\section{By Robert Nixon, M.B., Ch.B. LiverP.}

THE following cases of spirochrtal relapsing fever occurring in Liverpool are of interest in view of the large number of emigrants from Eastern Europe now passing through our ports:-

The patients, H. S. and B. S., two Roumanian boys, aged 15 and II respectively, were admitted to the City Hospital South, Liverpool, on Nov. 26th, 1920, from an emigrants' boarding-house with the diagnosis of measles. The history was as follows: They lef Houmburia on Nov. 9th, and arrived in liverpool, via Prague and Neither of the boys showed any were not deloused at Hamburg. the elder, H. S., complained of headache and malaise shortly after the elder, H. S., complained of headache and malaise shortly after the time of adyinger boy had appeared in normal health up to the time

H. S. on admission had a temperature of $103^{\circ} \mathrm{F}$. which rose the following morning to $105^{\circ}$, accompanied by expectoration of about an ounce of "rusty" sputum, and fell by crisis the same evening to $98^{\circ}$. Nothing abnormal could be found in the lungs and no Nov. Dec.

$\begin{array}{lllllllllllllllllllll}26 & 27 & 28 & 29 & 30 & 1 & 2 & 3 & 4 & 5 & 6 & 7 & 8 & 9 & 10 & 11 & 12 & 13 & 14 & 15 & 16\end{array}$

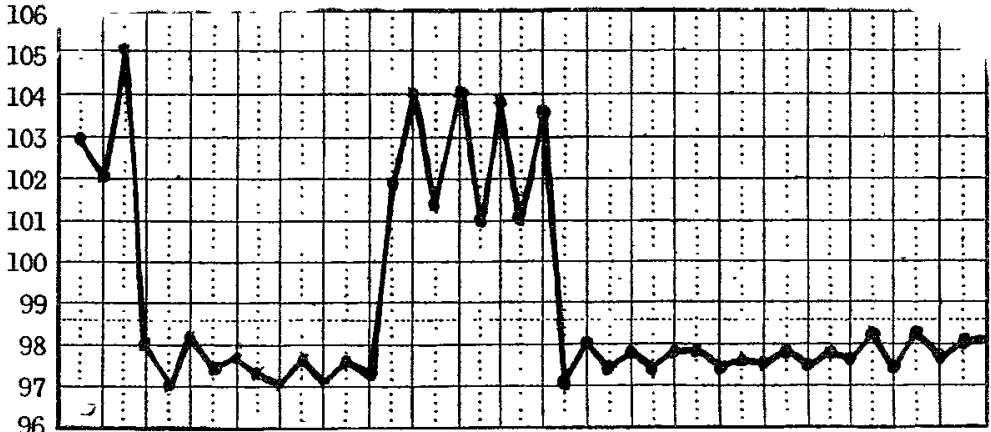

CHART 1.-H. S., aged 15

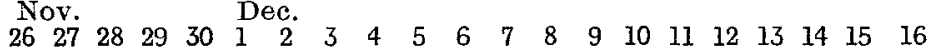

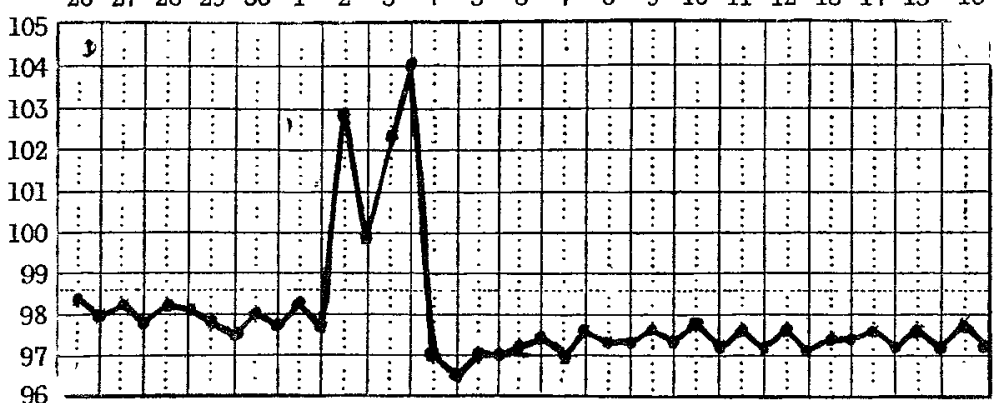

Chart 2.-B. S., aged 11 .

tubercle bacilli or pneumococci in the sputum. The younger boy B. S., appeared in normal health on admission. However, his temperature rose to $102^{\circ}$ on Dec. 2nd, and the following day H.S.'s fever recurred, again accompanied by expectoration of "rusty" sputum. Blood smears taken on Dec. 4th showed in each case spirochretes throughout the field in large numbers, exceedingly thin and in length about three or four times the diameter of a red blood corpuscle. H. S.'s blood still showed spirochætes on Dec. 6th ; but all subsequent smears from $B$. S. were negative.

Neither boy has had any relapse since Dec. 7 th, and both were discharged from hospital in good health and apparently completely recovered.

Liverpool.

\section{Stledical Socitetiss.}

\section{MEDICAL SOCIETY OF LONDON.}

Skin Disease: Its Relation to Internal Disorder.

A MEETING of this society was held on Feb. 14th, Sir FrEDERICK W. MOT'T being in the chair, when a discussion took place on this subject.

The opening papers, by Sir James GaLloway and Professor ARTHUR HALI, are given in full in the front part of THE LANCET of last week and the present issue respectively.

Dr. E. W. GOODALL said that he based his remarks upon an experience derived solely from an acquaintance with

Skin Affections connected with Acute Infectious Diseases of this country. The eruptions met with in the acute infectious diseases were acute and transient and variable, from a fleeting urticaria to a pustule which left a scar. The cutaneous phenomena of the acute infectious diseases were met with at different stages of an attack, but, as a rule, certain skin manifestations were met with at certain stages. They might be arranged in three groups: (1) the prodromal or initial rashes, (2) the eruptions characteristic of the exanthemata, and (3) the rashes of the post-acute or posteruptive stage. There might be a certain amount of overlapping, but, broadly speaking, the rashes were found at these stages. Except in the case of small-pox the prodromal rashes were common to certain infectious diseases, and some of the prodromal rashes even of small-pox were common to other diseases. In the exanthemata the rashes of the eruptive stage were con fined to each disease; the rash of scarlet fever did not replace that of measles, for instance, but these rashes might be produced by other causes.

With regard to the post-eruptive, post-acute stage rashes, these had also been termed "secondary" or "accidental" rashes. They occurred usually from one to four weeks from the beginning of the attack. They were common to all the infectious diseases with which he was acquainted and were either urticaria, macular and slightly papular erythema, or erythema marginatum. Although they were met with in all the infectious diseases they were relatively infrequent in each one of them. He thought that it would be granted at the present day that the cutaneous eruptions, whether special or common, of the infective diseases were not primary lesions, but were only one of many changes, visible or invisible, including more or less the whole body. The chief argument in support of this statement was the undoubted fact that a person might suffer from an attack, a serious attack, of most of the acute infectious exanthematous diseases without the presence of any exanthem whatever. The next question which arose was whether the skin lesion was due to changes in the structure or alteration in the functions of any particular internal organ. So far as he was aware, there was no evidence in favour of this view. It was a question of a general cell or tissue disorder. For many years past a great deal of work had been done on the question of infection. It would appear, how ever, that cutaneous eruptions of the erythematous class were not visible on the skin of the animals used for experiments. Indeed, it seemed to be difficult to affect most animals with the human infectious diseases, at any rate, in the same form as they assumed in man. Included in work which he mentioned was the experimental work on anaphylaxis and the clinical work on serum sickness. Nothing occurred in animals, however, which corresponded with ordinary serum sickness in man. He emphasised the fact that the rashes of serum sickness were always either urticaria, a morbilliform erythema, or erythema marginatum.

The question which he wished to discuss was whether the phenomena of serum sickness in man or of the anaphylactic rashes in animals threw any light upon the nature of an attack of an acute infectious disease in the human subject, and he wished to discuss the question chiefly in respect of the skin eruptions. There were some who held that an attack of an acute infectious disease was an anaphylactic reaction, and they would argue, in most instances, that an attack of serum sickness was also an anaphylactic reaction. In bis opinion, this was not true of an attack of an acute infectious disease, nor was an attack of acute infectious disease brought about in the same way as an attack of serum sickness. He thought that 